\title{
Creating intergenerational learning spaces: A collaboration between UNIVEN Community Engagement Programme and Dzomo la Mupo
}

\author{
Vhonani Olive Netshandama* and Nyadzani Dolphus Nevhudoli \\ University of Venda \\ "Corresponding Author: vhonani.netshandama@univen.ac.za
}

(Submitted: 10 August 2021; Accepted: 30 November 2021)

\begin{abstract}
This article is a reflection on a collaborative learning process between a university department and a community-based organisation in creating intergenerational learning platforms. The process entailed the coming together of school learners, university students and community elders in a university set up. Participatory Appreciative Action Learning Research was employed. Purposive sampling was used. Data collection methods approach included were semi-structured interviews, one on one individual interview and focus group discussion. Three generations, namely school learners, university students, and community elders, participated in selecting the learning areas. These included Indigenous Knowledge Systems (IKS), nature conversation topics, peace-building, manners and Ubuntu, social entrepreneurship, and health issues. The purpose of this initiative was to transfer knowledge, skills, norms, wisdom, and values, among generations, through a collaborative effort between an academic institution and a community. It was hoped that this would provide opportunities for lifelong learning and sharing of knowledge and experience among generations. The collaborative intergenerational learning (IGL) process opened with a series of focused discussions about how to bring to mainstream education (both basic and higher education), platforms for learning that should be inclusive of all forms of knowledges, including indigenous knowledge (IK).
\end{abstract}

Keywords: collaborative, indigenous knowledge holders, intergenerational learning, lifelong learning,

\section{Introduction and background to the study}

Universities are by their nature knowledge-intensive institutions. They have a layered structure from full professors downward to students. This structure is very useful in knowledge transfer and learning processes. Since it promotes knowledge flows against the gradient of the knowledge in a particular field, as professors they play the role of knowledge source for their younger colleagues and students. Universities, however, have difficulty roping in other forms of 
knowledges to the learning agenda. There are no platforms, for example, that promote a curriculum framework for intergenerational learning. Whenever there is suggestion to learn from the elders, the question of how one learns from the wisdom of elders come to play.

There is a necessity for developing awareness and educational programs following a transformational curriculum for intergenerational learning outside mainstream learning, but which directly influences curriculum transformation. Intergenerational knowledge, then, has proven essential to disrupting curricula and pedagogical approaches that attempt to standardize student learning and reduce teaching to a set of mechanized tasks (Maloney, et al., 2019: 266).

The fundamental flaw in the current curriculum process and system is that intergenerational learning from elders and Indigenous Knowledge Holders (IKH) is not sufficiently expressed or captured in mainstream learning. The findings of the study by Moichela (2017: 162) suggested that elders should be given a role in the planning of the curriculum as valid bearers of remarkable renaissances such as the African Family Renaissance (which is the nexus of Indigenous Knowledge Systems (IKS)) for the sake of posterity (Moichela, 2017). Contestations are often based on the difficulties of its formal coding in line with standardised practices. At the core of the challenge is that there are no platforms where learning about collaborative IKS and transferring wisdom is sufficiently entertained. Additionally, because of a lack of universal coding, such knowledge forms cannot be recognised, or utilised effectively to bring positive change to society.

University and schools comprise various generations on their own. Sanchez, et al. (2018: 1) suggest that 'the circumstance that schools [and universities] include people from different generations may make them multigenerational, but not necessarily inter-generational learning organizations' . This suggests that there is still some form of effort that needs to be put in place for intergenerational learning to take place. This is well articulated by Newman and Hattan-Yeo (2008) by the "Engaged University" concept.

A collaboration between the Department of Community Engagement at the University of Venda (UNIVEN) and Dzomo la Mupo (Voice of the earth) designed an initiative for a semistructured intergenerational learning program to establish the possibilities and the effectiveness of such program.

The collaboration process was complex and focused on an interdisciplinary process of knowledge creation through restructuring, sharing, and exchanging of insights at diverse group levels. It was an integration of the participants' lifelong learning and innovation that involved both explicit and tacit knowledge. It is a process that can either be stimulated or inhibited by many internal and external organisational factors. Very seldom does the intergenerational approaches focus on elders serving the youth through kin care or mentoring. Universities' learning systems also do not embrace ecologies of knowledges. To date, they have not managed to bring together different generations to work together in creating knowledge that has the same recognition and accreditation as other forms of knowledge in the education system.

Intergenerational learning can be facilitated in any range of contexts in which young people and elderly people come together, in mutual respect, to share activities. Newman and HattonYeo (2008) assert that such an enterprise takes place within programs specifically designed to 
bring together young and older people in shared meaningful activities. They continue that the process of intergenerational learning, at the family level assists the younger generation with knowledge about their history, thus, aiding the transfer of heirlooms

Intergenerational learning programs may be defined as "social vehicles that create purposeful and ongoing exchange of resources and learning between older and younger generations" (International Conference on Intergenerational Programmes cited in Newman and Halton, 2008: 32). Additionally, Hoff (2007) sees intergenerational learning as being primarily the enhancement of social capital through lifelong learning and that older people can be involved in community-based learning experiences for the benefit of whole communities. He argues that the process of intergenerational learning should occur beyond the family boundaries. This would ensure that the transmission of knowledge would be from all knowledge holders in the community to the younger generations, and vice versa, without any family restrictions.

From this approach, Hoff (2007) introduced a new intergenerational learning paradigm extra-familial (Newman \& Hatton-Yeo, 2008). The application of this paradigm, in a study by Newman and Hatton-Yeo (2008), showed correlations between intergenerational learning and positive social and personal developments in the lives of the students involved. In a resultant paper, the intergenerational learning benefits were comprehensively articulated. In addition, Hoff (2007: 127) has asserted that intergenerational learning, as far as knowledge and skills are concerned, could assist towards adapting to modern life and bridging the gap between the young and the old.

Intergenerational learning is always regarded as a platform that brings positive impact to the learning environment. Studies conducted in the United States by Pstross, et al. (2017: 160) attest to the positive impact of intergenerational programs in higher education settings. They found that through these programs the students acquired an understanding of aging and of services provided to older adults and they learned to interact better with older adults

Older people can generate community-based learning experiences not only for themselves but also for the young. Pillipson and Ogg (2010: 12) argue for a clear role for education and higher education in particular regarding this stronger intergenerational mix within traditional academic programs. Similarly, Kaplan and Sanchez (2014: 375), stated that intergenerational classrooms in formal higher education may constitute windows of opportunity to rethink the practice of teaching as far as they may become venues for triggering processes of intergenerational learning.

Aemmi and Moonaghi (2017) reiterates the transformational nature as they saw intergenerational learning program as a systematic transfer and interactions of knowledge, skills, competencies, wisdom, norms, and values between generations. For the authors, intergenerational programs may be defined as 'lifelong learning creates the opportunities for all generations to in-depth rethinking, education, learning and work (not necessarily jobs) that cause to enhance the quality of life' (Aemmi \& Moonaghi, 2017: 6714).

For the youth and children, Intergenerational Learning (IGL) can also improve academic performance and for the older generations, they can learn new information and technologies. In 
general, on this platform, the breadth and depth of learning activities improve and culture, values and traditions can be passed on from one generation to the other. Due to the age diversity, the learning then becomes rich with information and experiences that allow participants to stimulate, open-up and explore ideas stored in the different generations.

\section{Foundational Concepts of Intergenerational Learning}

The current higher education curriculum still largely reflects the colonial and apartheid worldview (Ramoupi, 2014: 271) and is disconnected from African realities, including the lived experiences of the majority of black South Africans. Most universities still follow hegemonic 'Eurocentric epistemic canon ... that attributes truth only to the Western way of knowledge production' (Mbembe, 2016: 32). It has also affected the rights of local communities with regard to their cultural activities and linguistic relevancy to education, the indigenous local communities' world views of learning and of knowledge production have also been affected.

Local knowledge is regarded as unscientific, with limited contributions to the current information world; in other words, the type produced by institutions of higher learning. In most cases, intergenerational facts relevant to teaching and learning has not been evaluated by institutions of higher education. This is the situation, despite the fact that results from the few studies conducted show that it promotes the concepts of pluriversity and subversity in the community, thereby contributing to knowledge production.

Scholars, such as Cortina and Earl (2020: 4), have argued that the concepts of pluriversity and subversity are constructed not as a reified version of traditional customs, but rather as a continual process of critical dialogue and reflection that also renew and strengthen indigenous political and moral philosophies. These concepts both promote self-direction and autonomy in higher education, although, this is often an uphill battle; for subversity models, they raise questions about what kind of knowledge and resultant degrees would be recognized and legitimated by the state and its citizens.

Pluriversity approach in IGL has answered challenges that affect the communities, while subversity was more into engaging communities in knowledge production through the creation of intergenerational learning. Cortina and Earl (2020), in their study, story-telling was used as a form of eco-mapping dialogue, as an alternative of transferring knowledge; that is, instead of only the elders narrating stories while the younger generation listened, learning took place in focus-group discussion and round-table discussions. Participants learned several things, such as food systems, and they are now able to draw ecological traditional calendar and concepts such as cultural biodiversity were discussed among the different generations. In IGL, the subversity approach, therefore, encourages individuals to engage in exchange of knowledge.

Higher Education needs to incorporate indigenous languages, cultures, and epistemologies into their curriculum as this represent attempts to decolonise these learning institutions, and to contest the unequal power relations that prevail within universities and countries.

In a study, with Dzomo la Mupo (DLM) which is a community organisation, the mapping process of cultural eco-calendar involved elders, knowledge holders as well as the youth and 
school children as the latter were encouraged to participate through integrating what they have learnt in schools into the discussions. Elders shared their life experiences, their knowledge, while the younger generation implemented the knowledge shared in order to realize the needs of local communities. For example, in the study, knowledge was shared on the impact of climate change on agricultural, the potential of the establishment of mining on people' s livelihoods, and the significance of sacred sites. The final outcome was to raise awareness of the importance of integrating intergenerational learning programs into main-stream education as a way to embrace intercultural, indigenous, and current scientific knowledge systems.

In essence, the engagement between the youth, elders from the community, high school children, and Dzomo La Mupo knowledge holders outlined the benefits of intergenerational learning as the following: establishing a process of intergenerational learning and practice which can be relationally and reciprocally experienced and can be impactful even with future generations; the need for integrating IGL for a relevant and responsive education system which will attend, comprehensively, matters related to communities.

\section{Aims and Objectives}

The study was concerned with space-creation for collaboration among different generations in communities. This was aimed at the initiation of collaborative action research looking at engagement and advocacy programmes to create intergenerational communities of practice that acknowledge knowledge ecologies.

The objectives of the study were the following: (1) To determine the extent to which inclusive intergenerational learning can take place in universities, i.e. IGL that incorporate other forms of knowledge, outside of the mainstream; (2) To mobilise, identify, and engage relevant institutions/role players who should be involved in the development of an intergenerational learning curriculum for specific priority areas; (3) To sample and develop a curriculum, systems and processes for intergenerational learning in a university context; and (4) To implement and evaluate a selected university' $s$ intergenerational curriculum which demonstrates an inclusive infusion of intergenerational knowledge.

The specific research questions of the study were:

(1) To what extent is intergenerational learning that is taking place in a university incorporating other forms of knowledge, that is, outside of the mainstream?

(2) What are the processes between DLM and CE in developing a collaborative intergenerational learning curriculum?

(3) Which institutions/role players are involved in intergenerational learning?

(4) What is the nature of the curriculum, systems, and processes for intergenerational learning in universities?

(5) What are the results of an implementation and evaluation of an inclusive infusive curriculum on intergenerational learning in a sampled university? 


\section{Literature Review}

\section{The Concept of Intergenerational Learning}

There seems to be no standard definition for intergenerational learning in the literature; however, it has been conceptualised similarly in different fields as an interactive process between groups of people from non-adjacent generations engaged in a relationship where one or both parties learn Stephan (2021: 451). Sociology describes an intergenerational learning platform as an interactive process between a grandparent and a child or youth that usually takes place within a family situation and leads to better understanding of the youth' s role in the family unit as well as society in general. This assumes IGL as a way for socializing the next generation in the mores and values of society. (Ropes, 2013: 717). Due to the breakdown of the extended family, public programmes are necessary to complement the learning that would take place in the family. Such programmes help reduce negative stereotyping on both sides. Among others, such programmes promote improvement of social skills, feelings of inclusion and empowerment (Newman \& Hatton-Yeo, 2008).

These differences amongst scholars in defining intergenerational learning show a limited conceptual understanding of the notion of formal intergenerational learning. In North America, the term 'intergenerational programs' is used to refer to those activities or programs which increase cooperation, interaction and exchange between people of different generations; these programmes enable participants to share their talents and resources and to support each other in relationships that benefit both the individuals and their communities. (Corrigan, et al., 2013: 119).

Similarly, intergenerational learning is always used for a broad range of activities in which the participation of people of different age seems to constitute the only common ground for all these types of learning activities (Findsen \& Formosa, 2012: 145). These activities usually generate learning outcomes for educational purposes, even though they may or may not be the primary focus of the activity.

Hake (2014: 155) identified the three main types of intergenerational learning practices as transfer, transactional, and transformative learning. Transfer learning concerns linear communication and acquisition of knowledge, skills, and sensitivities between generations. Transactional learning involves the negotiation of voluntary and mutual exchange between the generations of knowledge, skills, and sensitivities through learning exchanges. Transformational learning refers to the mutual development of knowledge, skills, and sensitivities between the generations in self-organized learning communities based upon commonly shared problems in day-to-day life in streets, neighbourhoods, communities, action groups, and social movements (Hake, 2014).

The concepts of IGL revolves around having a variety of community stakeholders working together. One example is that of a Scottish organisation - Generations Working Together (GWT) - which aims to bring diverse people together in purposeful, mutual-beneficial activities which promote greater understanding and respect between generations and contribute to building more cohesive communities. Johnson (2008:5) alludes that intergenerational learning occurs 
when projects or activities are purposefully planned to include one, or several, learning aims and outcomes across generations; when that happens both sides learn from or with each other, to gain skills, values and knowledge. This means that the learning should be a reciprocal process between different generations (Beth Johnson Foundation, 2008).

IGL approach is then regarded as the best way to describe a style of working together that can lead to many different activities and the outcomes of such can be applicable in knowledgecreation in institutions of higher learning. Manion (2012: 387) suggests that intergenerational learning involves different interests across the generations and can be employed to address the betterment of individual, community, and ecological well-being through tackling some problem or challenge. A definition of intergenerational learning programmes indicates that it is a lifelong learning that creates the opportunities for all generations to in-depth rethinking, education, learning and work (not necessarily jobs) that cause to enhance the quality of life (Aemmi \& Moonaghi, 2017: 6714).

According to Cohen-Mansfield and Jensen (2017: 260) Intergenerational programs contribute to reducing the generation gap and promote positive relationships between the older and the younger generation.

Corrigan, et al. (2013: 119) label IGL as a conceptualised process of an informal process taking place in families, tribes or other such grouping which does take place beyond a normal classroom environment. Similar to the concept, Kolb and Kolb (2005: 193) quote John Dewey' s reflection on the need to foster experiential learning in education: '[There is a] need for forming a theory of experience in order that education may be intelligently conducted upon the basis of experience' .

The Institutions of Higher Learning can form theories of experience, based on generations, through their engaged curriculum. Newman and Hatton-Yeo (2008: 36) explain that an 'engaged university' can provide an opportunity for the promotion and examination of intergenerational learning that currently is under-researched; there is a need to identify best practices as models for replication, for example, such practices would develop mutual learning relationships among different generations and help to develop social capital and social cohesion. Each generation learns about the other and gains a better understanding of the other generations' strengths, fears, and weaknesses since each generation has resources which are of value to the other. This strategy will ensure the sharing of areas of concern which would aid in providing a sense of empowerment among generations. An engaged practice of learning seems to bring an understanding of different generations in the process, which makes learning relevant and valuable within the immediate context.

Wrenn and Wrenn (2009: 261) stress that learning is best achieved when students are actively involved in a cyclical process that includes observing, applying, reflecting, and sharing their experiences. They further said that learning is enhanced when it arises from environments where the traditional roles of teacher and students are expanded to include teacher as student and students as teachers. They are more authentic within the framework of an outside community programmes and organizations which include elders. These initiatives have greater significance 
when the achievement of organizational objectives depends on students and elders in the communities' contributions.

Within this context, Perrin (2014: 1) believes that the theory-practice connection is achieved as the learner progresses through a cycle of experience, concept, reflection and action. This cycle is most effective when students are brought into direct contact with concepts and issues that they had addressed in class discussions and readings. When the connections are salient, experiential learning guides students to comprehend their concrete personal experiences within a more abstract theoretical framework; this can result in increased motivation and personal development (Perrin, 2014).

The advocates of intergenerational programs assert that these are developed to foster meaningful interactions among members of different generations. Collaboration in intergenerational learning enables different age groups to discover each other, and helps to address serious social policy issues. In this regard, age diversity should inform the curriculum developers so that the resultant document would create positive attitudinal change among children and elders (Cummings, et al., 2004: 92).

Additionally, Sharma (2017:1) offers the following as some of the main reasons intergenerational knowledge-creation practices should take place: firstly, they recreate links between generations, making it possible to promote intergenerational understanding and respect; secondly, they contribute to the identification and development of individual competencies for a more inclusive society; thirdly, they foster dialogue and encourage collaboration; fourthly, IGL exchange significantly fosters solidarity, active citizenship and personal development; and lastly, they can strengthen teaching quality.

Of the many reasons for intergenerational learning programs, one of its most significant benefits is that the initiative works in two ways - young people can often teach older people about new issues, especially, in the world of technology, while the older generations can also teach the young generation cultural norms, values, and respect Johnson, (2008:7). Intergenerational learning should therefore be promoted for all the knowledge fields and the universities should interrogate and revise some of the traditional curriculum processes and content by developing new approaches and new visions; these are issues for which they are not prepared nor doing so as to promote intergenerational content in all fields. (Johnson, 2008).

The inherent concepts and definitions of intergenerational learning from different scholars throughout the literature supported the broad vision of this study which include an appreciation of the value of a two-way transfer of knowledge, expertise and insight between senior citizens, academics, community youth, and university students.

This study was interested in creating intergenerational learning spaces based on a collaboration between UNIVEN Community Engagement Programme and Dzomo la Mupo community organization. This was to enable dialogue among the generations for the acquisition of value and knowledge, based on the lived life experiences of the generations. 


\section{Intergenerational Learning and University Curriculum Development}

The relevance of inclusive knowledge among generations is not considered in many universities' curriculum, in teaching methods, or in other formats of the learning process. Professionals developing intergenerational programs often do not have any formal training in intergenerational learning even though many guidelines, courses, and examples of how to plan, develop, and evaluate successful intergenerational activities is available. Intergenerational practices arose as answers to demographic aging, longevity, and societal problems, so they tend to be perceived as a social asset, rather than as a teaching resource. Theoretical knowledge on intergenerational relationships emerges from practice more often than from research. Another argument that can, therefore, be invoked to justify this lack of interest is the fact that intergenerational learning has not been measured yet and the knowledge and skills gained by participants are not, usually, tested or examined. Professionals involved in intergenerational practice usually have an academic degree, qualifying them to work only with a specific age group, but not to promote dialogue and learning among different generations (Pinto, 2011).

This, once more, highlights not only the need for an inclusive education system on intergenerational learning, but one that enables such a relationship to exist. The last point cited by Pinto (2011) from Jarvis (2009) touches on individualism, where the scholar has discussed that the world consists of "networks of people" , co-existing and learning from one another; this disputes the idea that learning is a process that individuals experience alone. Pinto (2011) has suggested that although interests may be lacking in relation to carving intergenerational learning as a discipline, intergenerational knowledge-creation practices, along with its practitioners and research should not be neglected.

\section{Bridging the gap through Intergenerational learning}

There is an intergenerational service-learning program called WISE (Working Together: Intergenerational Student/Senior Exchange), which was designed to promote intergenerational understanding and communication, thereby, closing the existing gap between the young and the older generations.

According to Pinto (2011), as much as intergenerational learning activities are not included in the curriculum and in teaching methods, there will, always be a need to bridge the gap. One of the ways to close such gap is through conducting studies that seek to highlight the value added by intergenerational relationships to teaching and learning. Among other points mentioned by Pinto (2011) on why intergenerational relationships are not included as a discipline in the European educational system, the scholar has pointed out that those with academic degrees are only qualified to engage or work with a specific generation as opposed to including insightful dialogues across different generations.

Intergenerational is aimed at drawing attention to the learning needs of individuals as members of multigenerational communities. Jarvis (2009) notes that the richness and the multiple interpretations about what is an intergenerational learning environment and which might be the best methods to use in a given situation, can only improve the quality of the practice. Lifelong 
learning should be envisaged as intergenerational learning, although, in practice, people still follow paradigms that fragment teaching and learning and hamper the acquisition of intergenerational learning as a form of lifelong knowledge acquisition. Perhaps to close that existing gap, it is time to teach people as "apprentices in progress" rather than receivers of knowledge on predetermined stages of life.

Through several sessions held, this study discovered an advantage in sharing knowledge amongst generations, therefore, the crucial part in closing the gap identified in this study will be when Dzomo La Mupo elders are familiarized with modernity through the participating university students who in turn would have acquired non-current knowledge from the other generations; this would confirm reciprocity. That would make the lives of all participants easier and also relevant to the modern era and social requirements. Such knowledge may relate to, for instance, lessons in English grammar, using smart phones and other gadgets. This then initiates the question: Does one generation take it as its responsibility to make sure that one generation is familiar with the next generation?

Andreoletti and Howard (2018) have emphasised in their study that there are changes that have occurred within the last 50 years around technology and social issues, and according to Twenge (2013: 14) such changes have played a role in informing our values and has had an influence towards the younger generations being self-oriented. This was also visible through the existing disconnect of values among some of Dzomo La Mupo's elders and younger generations; the implications of such changes on intergenerational learning remains a question for more research.

Furthermore, they focused on bridging the gap that has been acknowledged in classrooms where younger adults have shared their anxiety when it comes to interacting with older adults due to the assumption that both generations may have nothing in common. This concern was attended to in how the collaborative engagements in the study with Dzomo La Mupo community allowed the participating university student a platform to practice what they had learnt in class and further their experience level.

The results of their article have suggested that the inclusion of a few interactions between the older and the younger generations during the semester had a positive effect on the attitude of the younger generation towards the older generation. For example, the inclusion of service learning in courses ensures that more students can experience the benefits of high-impact traditional knowledge. Older people, hence, were found to have increased their social contacts as a result of interacting with younger people, and younger people have been reported to understand older people better.

\section{Research Methodology}

The study applied Participatory, Appreciative Action Learning and Reflection (PAAR) approach. Kearney, et al. (2013: 113) mentioned that PAAR has the potential to: (1) promote mutual learning and development; and foster the cascading of learning and knowledge to others in the community, not only that but it can also co-create knowledge that is relevant, contextualised and 
useful, both for meeting community needs and producing research output as required of universities.

Meanwhile, Wood and Zuber-Skerritt (2013: 10) refer to the democratic, participatory, and emancipatory values and behaviours that comprise the paradigm of PAAR as the 7Cs: communication, collaboration, commitment, coaching, critical reflection, competence, and character building. Furthermore, Lack of Academic Standardization, Great Dependence on researchers, Paradox in power redistribution and lack of commitment of participants were identified as factors that can make PAAR ineffective when solving problem in organizational learning (Wood \& Zuber-Skerritt , 2013)

According to Ghaye, et al. (2008: 362), PAAR enables individuals and groups to move forward, to improve their working practices and lives in particular communities and contexts.

Participatory Appreciative Action Learning Research was employed. Purposive sampling was used. Data collection methods approach included were semi-structured interviews, one on one individual interview and focus group discussion. The approach in the study allowed for the creation of space for dialogue between different generations. In order to answer the research questions and promote public platforms for intergenerational engagement, we conducted ten focus group discussions with a heterogeneous group of ten participants for each table consisting of three elders, five learners and two university students per table. To initiate the discussion that entailed 3 sessions, we provided eight themes that were initially predetermined by elders in separate preparatory sessions. In each category, the elders got an opportunity to serve the group as a co-facilitator and a participant observer. The discussions through different sessions with the participants provided the following results that are also aligned with the research questions of the study.

\section{Results}

An IKS Heritage Day symposium was hosted by University of Venda-Community Engagement in association with UNIVEN AIME, Marude Secondary School, and Dzomo La Mupo. The symposium was aimed at Creating Intergenerational Learning Spaces. It was a fun-filled, lesson- or activitypacked environment which allowed learners opportunity to interact with elders in a university learning environment. The symposium was also aimed at educating learners about eco-mapping, nature conservation, preservation of respectful manners and Ubuntu, as well as indigenous entrepreneurship development and career choices. The four echo-mapping topics emphasised were, storytelling, manners, food and health, and love and Ubuntu.

The focus group discussions during the workshop were divided into ten groups. Besides creating space for intergenerational learning, the workshop aimed at exploring the role of storytelling in enhancing the transmission of indigenous and local knowledge for biocultural conservation in Venda, South Africa. The workshop was designed to bring together a range of stakeholders, including academics, representatives of community-based organisations, school teachers at primary and secondary levels, and curriculum advisors in the Vhembe District, Limpopo Province, South Africa to discuss and debate the importance of storytelling for the 
revitalisation and transmission of indigenous and local knowledge as an educational tool for schools in the Venda region. The intended outcomes of the workshop were to develop and pilot a toolkit detailing storytelling approaches and exercises that teachers can use in a classroom setting to promote the transmission of indigenous and local knowledge among the youth.

\section{The importance of advancing story telling methods}

Storytelling is a powerful method that has revealed a range of topics, specific to a culture, social context, and nature; participants became familiar with these topics through group discussions and feedbacks. Storytelling allows students to combine new knowledge acquired with existing knowledge, values and everyday behaviour. Students were encouraged to tell stories about new information they had learnt. These learning activities did not focus on theory, rather, it integrated that information with the younger generation' s practical knowledge.

The role of indigenous and local knowledge for biocultural conservation, potential barriers influencing knowledge transmission from elders to youth, and the importance of storytelling for meeting social and learning outcomes were discussed thoroughly. Participants were given the opportunity to try different storytelling techniques that could be used in the classrooms.

Attention was also given to discussing the needs and interests of primary and secondary school teachers in relation to the national curriculum, the types of support materials they use or would like to use, the physical constraints and opportunities of the classroom, and preferred target ages groups to integrate storytelling approaches. These areas were focused upon in order for knowledge to be transferred from the early stages of the youth; this ensures that by the time they come to the university, they would possess some indigenous knowledge from the elders.

Learners were also taught about the importance of interconnectedness of human beings and all living beings, as well as the power that they have within themselves to protect and change the universe for the better. The big question was also how to make IKS sustain life, hence, the elderly people were urged to teach the young ones about life and their culture.

\section{The ecological mapping as a way of storytelling}

The different generations, not only wanted to learn from each other, but they also sought space for new learning. For example, the elders wanted to remember their life-time experiences so that they could share the knowledge with the youth and children. Teachers too wanted to teach about this knowledge. The ecological cultural calendar helps teachers to find space for integrating indigenous knowledge system into the school' s educational system, for example, in different subjects and learning areas

The ecological mapping method was used to provide the pupils with an indigenous knowledge views, while focussing on cognitive-wide learning. This was done through narrating the story by one person and the group listening. The younger generation engaged in learning from the elders by the pupils asking questions about the topics during their table discussions. The elder' s response approach included writing and drawing sketch map during the dialogues. This activity involved participatory learning as the young people presented questions on the basis 
of their own experiences, modern world issues and in the process the youth were filling in the gaps on how indigenous knowledge, their culture, and elders play roles in their lives; the elders explained and shared their experiences.

\section{Food and Health}

On the topic - The Value of Good Nutrition in our Community - participants noted that having a good nutrition leads us to have a healthy community or society that does not suffer from diseases. Most people know that good nutrition can help in physical activity that can help maintaining a healthy weight body, but it does not only mean that - the benefits of good nutrition go beyond weight issues. Good nutrition also helps in decreasing the chances of developing various diseases that can be caused by unhealthy diet. Through a lengthy discussion, participant also discovered that, indeed there is a huge chance of not being attacked by diseases, if one is actually maintaining good nutrition.

\section{Love and Ubuntu}

IKHs' are needed for peace building and Ubuntu in the community. The history of indigenous knowledge systems in solving disputes and peace building is well-noted in most African countries. This dates to the pre-colonial era where elders and community leaders met to resolve local conflicts and disputes using their own indigenous mechanisms. Out of the discussion held during the different session, the elders mentioned that peacemaking and peacekeeping missions in African countries have been used as ways of addressing protracted conflicts in countries. The elders highlighted to the younger generations that government should start to re-think what could be done to bring about sustainable peace in African families and countries.

\section{Education and Curriculum practitioners}

The Department of Education has been engaged in most of the University of Venda' s previous workshops hosted in matters concerning academic space. The Department has also been engaged in violence-prevention workshops, wherein the University of Venda collaborated with the Germany-based Nuremberg University. With the assistance of elderly people, participants come up with Afrocentric views of addressing violence at schools, and in the university environment. This was because one of the articulated strategic outcome of community engagement in the South Africa context, in regard to social responsiveness, is to contribute to the development of students, communities and higher education institutions with, social responsibility, humaneness and social justice. This is in response to the concept of 'Ubuntu' as one of the founding principles of a democratic South Africa' (Van Wyk \& Higgs, 2012). A person with Ubuntu is open and available to others knowing that he or she belongs to a greater whole (Tutu, et al., 2014) and whatever happens to the individual happens to the whole group, therefore, the individual can only say: 'I am, because we are; and since we are, therefore, I am' (Mbiti, 1990). 
Engaging all these stakeholders was an attempt to shift from adversarial and fragmented orientations to more relational-appreciative mindsets. This is where the practical creation of learning spaces can be done through the decolonization of knowledge approaches, learning and acting, as well as co-learning to capacitate students, staff, and the community at large.

\section{Implications}

The study offers suggestive evidence regarding the significance of deliberate creation of intergenerational learning platforms for various reasons, including access, knowledge coproduction, co-learning, and preservation of indigenous knowledge. It also implies that more funding needs to be allocated to such engagements that support and promote intergenerational learning activities.

The findings of the study also appear to support the argument for strengthening social compactness; this is based on reciprocity and a recognition that people of all generations are bound together with an overarching goal of intergenerational is learning. On the face of it, this would suggest that IGL may be an important factor in bringing people of different ages, races, and cultures together; to promote values in education that will enhance Intergenerational collaboration-driven research, and engagement between the University of Venda and the surrounding communities.

When intergenerational learning is implemented through the educational agenda, it will then be an opportunity for the institutions of higher learning to promote learning between generations and then there will be an increase of awareness and innovative policies implemented, based on intergenerational learning.

These findings mean that intergenerational learning may redesign the links between generations and make it possible to promote norms and values of cultural groups. It, however, does not mean that the approach cannot improve the academic performance of the younger generations or refresh their creative processes and open-up the exploration of ideas towards the younger generations' education.

\section{Challenges and Lessons in a Partnership with NPO-DLM for Intergenerational Learning}

\section{Importance of Patience during a partnership}

This partnership with a non-profit organisation (NPO), namely DLM, for intergenerational learning taught us the urgency of patience. First of all, it was a fascinating opportunity to have several dialogues, to listen, and to learn from a lifetime of experience delivered by the older generation although sometimes they were a quite repetitive in what they were explaining. At first the younger generation seemed not to understand the need for this partnership which was caused by the gap between the two generations, and the stereotyping that occurs - that the elders are the generation that does not contribute anything to the society, and this therefore makes them unable to understand how the partnership would work. Patience was essential to allow the younger generation to get the gist of having the DLM elders in this partnership. 


\section{Unequal Partnership}

DLM is an organisation that is formed by the older generations including indigenous knowledge holders, elders from the local communities, hence, the partnership was between DLM, academics, and pupils so that there were two or more generations involved. These were generations that do not learn or teach the same content nor in the same context. The content priorities in the engagement, therefore, would not always match, and that would often lead to unequal partnership in many respects. It was important during this partnership to have activities that will purposefully enhance the spaces for intergenerational learning and education in order to have an equal partnership among participants.

The circumstance during this partnership with DLM was a challenge because they did not have the same agenda and understanding of learning; therefore, it was important that during this kind of partnership to have activities that will purposefully enhance the spaces for intergenerational learning and education, in order to have an equal partnership.

\section{Benefit Sharing}

Collaborations among the different generational groups during this occasion also demonstrated the impossibility of benefit sharing. Benefit sharing is closely related to the concept of partnership between DLM as a knowledge broker. This concept of impossibilities of benefit sharing is associated within the context of $\mathrm{IKH}$, academics and the pupil as it demands knowledge sharing across different contexts.

It was not very difficult during the IGL workshop to shift from "succession of knowledge" to "co-creation of knowledge". Knowledge sharing is a process in which what the younger generation learns from the elders is not sufficient. The occasion also had limited benefit sharing; this was associated with the fact that the young generations during partnering were interacting more with their peers instead of cross-generational interactions.

From the viewpoint of intergenerational learning, difficulties with benefit sharing is a worrying phenomenon that underlines the need for more intergenerational learning between NPO and academic institutions to support a lifelong learning.

\section{Sustainability}

Intergenerational learning is being asked to do more than ever to solve social problems which include sustainability of solutions. All stakeholders stand to benefit immensely by drawing on learning platforms; however, one challenge identified during the partnership was to develop the means to support practical implementation strategies during the engagement and to sustain them to enhance future partnerships among intergenerational learning platforms. This is because there is a lack of investment in a partnership between the education entity, business, NPO, and the government, due to the fact that these stakeholders are not joining hands in supporting the initiatives; this makes it extremely difficult to generate sustainability. It is, hence, necessary to 
educate the academia, students, the education administrators, and the government at large about the importance of this aspect in the learning platform.

\section{Difficulties in registering IGL as a learning area}

The process of registering learning areas is still euro-western and bureaucratic exacerbated by the dominant paradigm. This is because policy makers, practitioners, and academics have not yet realized that intergenerational learning could play a great part in the education system, however, Intergenerational learning practice policies at the turn of the millennium are showing an interest in looking more closely at intergenerational learning and emerging it in policy and in a number of academic disciplines.

Euro-western paradigm curriculum in most of the institution in South Africa promote white supremacy and dominance, as well as stereotyping in education. The higher education curriculum still largely reflects western ideologies and that shows a disconnect with the African view; this does not promote intergenerational learning as one of the key learning areas in the curriculum. The existing learning areas make it hard to register IGL which is seen as not developing student' s critical and analytical skills which ought to move the African continent forward.

\section{Methods of ensuring a sustainable intergenerational curriculum}

The definition of sustainability in the context of this study focuses on creating lasting solutions through intergenerational learning activities. It poses the question on how to raise the next generation of leaders through the process of IGL. As a method to ensure sustainable intergenerational curriculum, there should be amendments of institutions' policies to support intergenerational learning in education.

An article - Generations Working Together (Johnson, 2008) - states that in order for the learning to become embedded in the curriculum or learning objective, it is crucial to evaluate intergenerational content against the aims and outcomes of traditional education content; this means that stakeholders have to - set the learning aims and outcomes before the whole process commences, that the journey from start to finish is recorded and they know the starting point / or the gaps in knowledge of the learners.

Now, looking at how this study/initiative was planned, its aims and objectives were to create an intergenerational learning space through a collaborative effort between UNIVEN and Dzomo La Mupo which is a community organization. In this context, the term 'collaborative effort' refers to working together to establish a curriculum that will enhance the creating of space for intergenerational activities through institutions of higher education, such as University of Venda. The finding of the study also covered issues such as collaborative action in a society that would benefit from the education system.

Togonu-Bickerstet (2014: 221) stated that intergenerational programs are built on the assumptions of who will benefits, what is benefited, and what contribution intergenerational interactions make in facilitating the attainment of developmental goals for participants, and that of lifelong learning process. Finding responsible and enthusiastic adult models of these 
assumptions will influence adolescent learning in a far more positive manner than much of what is done in our current intergenerational school settings. The fact is that stakeholders should be ready to go outside their comfort zone in order for IGL to be implemented. The need for the old generation involving themselves in the education systems needs to be emphasised and formalised.

The younger generation on the other hand should welcome the older generations' thoughts. Gallager and Fitzpatrick argued that sustainable intergenerational practice is facilitated by strong pedagogies that support active and relational learning across the life-course and by being embedded in robust community networks. Beynon and Lang, from a Canadian context, organized their paper around the idea that schools need to become and be seen as welcoming, thus, being accessible places of lifelong learning from infancy to elder hood. This is to emphasise that the young and older generations have to come together and carry out this curriculum transformation mission as early as possible.

In line with this study, where a space for intergenerational learning was created with the purpose of bringing changes to the communities and promoting the education institutions to review their curriculum, issues such as morals and manners had to be considered. Respect among generations is necessary as the purpose of such is to sustain the issue of lifelong learning process, hence, all stakeholders were involved in the process.

This curricular-based initiative has also motivated many individual teachers to take responsibility for the success of the program; these teachers were prepared to serve as volunteers and include the proposals in their classrooms. This is based on the certainty that a curriculum is flexible and can undergo constant amendments; however, if the stakeholders are not willing to put this into practice, intergenerational learning task cannot be carried out.

The responsible stakeholders should take part for the curriculum to be implemented with ease, thereby, it will be possible to see the advantages of intergenerational learning. As stated by Boström (2007). Intergenerational learning is not only about transferring knowledge, but also interacting with and understanding each other better. Furthermore he stated that intergenerational learning improves young people' s attitudes towards older adults, and also promotes their academic achievement. (Lyu, et al., 2020: 837)

\section{Discussion}

The initiative - Creating Intergenerational Learning Spaces: A collaborative between UNIVEN Community Engagement Programme and Dzomo La Mupo - centered all the focus group discussion that took place during the event. High school learners, UNIVEN students, elders from Dzomo La Mupo, and academics from UNIVEN were very happy to be part of this intergenerational learning session as it was a learning opportunity for all, particularly, the younger generations who had a productive. During the dialogue everyone was permitted to can say whatever they know and understanding in their group discussions. Each group concluded that the discussion around the different topics was a success, stressing the fact that intergenerational dialogue is regarded as very crucial, especially, from the notion of wanting to learn from each 
other. In Venda we have a saying: "A huna ano divha zwothe na hone a huna a sa divhi tshithu" which simply means "I know something that which you don' t know, and you also know that which I don' t know". The concept is relevant and promotes the issue of collaboration space for learning from each other.

Intergenerational learning circles are based on different generations, accompanied by their own specific views, attitudes and values. Elders connect with the youth and enable the teaching of our history and the importance of traditional values and assets, like our languages. The identity and values of a particular culture is learned when there is learning and teachings from one generation to the other through intergenerational discussion.

Through the group discussion, various and vital issues, such as Mikhwa, Mulalo and Zwiliwa and Mutakalo were learned. There is an increase in the belief that intergenerational dialogue would overcome segregation, an unwelcome norm in today' s modern societies.

The younger generations, represented by pupils from Marude High School, both girls and boys, and UNIVEN students performed $U$ losha in Tshivenda, which is a form of greeting and showing of respect to the elders in the Venda culture. The young ones were stimulated to understand the role of culture and indigenous perspective in all areas of life, for example, through Mikhwa (translated as "good manners" ) and u losha (translated as "greetings" ). The elders explained that children should learn to respect, by learning $u$ losha from their childhood. The older generation responded to the questions raised by the youth on what constitutes good manners and how these good manners are learnt; elders emphasised that children are supposed to be taught that from their early childhood. The discussions around how young generations should learn norms and cultural values through interaction with elders were held through different sessions. Furthermore, there was a session where an exchange of knowledge about food and heath, and love and Ubuntu took place.

The issue of power dynamics during the collaboration with the DLM organisation was a challenge. Power dynamics and trust affected the strategic planning of the workshop and participation during the workshop. The DLM knowledge holders and the elders from the community had doubts about whether to continue with the partnership; some of them at the beginning of the workshop focused on challenging topics such as who has passion for intergenerational workshops, language of respect, non-judgmental approaches and the establishing of connections; these were all part of the power dynamics. Power dynamics here is described as the formal authority to make decision and who controls what, and who has the authority to control ideas.

It was apparent that power dynamics had to be consistently monitored in order to have a meaningful intergenerational learning environment that would enable participants to look for opportunities for generations to share their learning experiences. Flattering the hierarchy before the workshop influenced the DLM and other stakeholder to acknowledge intergenerational diversity in the partnership.

Intergenerational diversity in the study refers to the representation of different generations working collectively for driving organisational strategies. The partnership presented an 
opportunity for learning and curriculum transformation, hence, the issue of power dynamics amongst stakeholders was also a challenge and should be looked at as such challenges can have a significant impact for future intergenerational learning activities. This need requires that all stakeholders involved need to take a close look at power dynamics during any collaboration.

This collaboration between UNIVEN community engagement programmes and Dzomo la Mupo (DLM) created a space for workshops and different sessions for intergenerational activities. The participatory process stimulated the young and the elders to interact, with motivation and interest. Young generations were taught about the importance of interconnectedness of human beings and all living beings and the power that generations have, within themselves, to protect and change the universe for the better. The other major question was how to make IKS sustain life, hence, the elderly people were urged to teach the young ones about their culture, early. The process of collaboration with DLM on intergeneration learning intended to put to practice how to disrupt hegemony, be inclusive, and obtain the inputs of elders in the knowledge coconstruction project.

\section{Conclusion}

The trademark of a progressive society and culture is the degree to which it generates, develops, maintains, grows, exploits and protects its knowledge base. Knowledge holders are currently unable to protect their knowledge base nor co-create knew knowledge due to challenges relating to negative stereotyping and denegation of indigenous knowledge.

From this collaborative intergenerational engagement, some questions asked were: What is the benefit of creating space for intergenerational learning especially within a collaborative platform? What critical reflection and examination of the current status of intergenerational learning status quo should stakeholders be frank about? During the study, we identified and interacted with the knowledge holders from a community-based organization, pupils from the nearby secondary school as well as UNIVEN students and academics. Several lessons were learnt from the dialogue and the presence and active participation throughout the created space contributed much to the lessons learnt.

The continuing challenge is to have patience when engaging with elders in the collaboration of intergeneration learning activities, to have an equal partnership for the benefit of sharing; this was also an issue that was raised in one of the sessions held during the workshops. Another point should be to encourage love and Ubuntu in the community and socializing through the passing down of knowledge from one regeneration to the other generation through collaboration and partnership. Creation of such a learning space will be possible through the promotion of an inclusive curriculum that supports intergenerational learning as a learning area.

\section{Recommendations}

To what extent is intergenerational learning that is taking place in a university incorporating other forms of knowledge, that is, those that are outside of the mainstream? 
The extent to which a university can incorporate intergenerational learning depends on the elderly sharing knowledge with the younger generations, although, it seems the younger generation lag in sharing knowledge with the elderly. The youth possess knowledge, predominantly technological, which could be shared with the elderly for them to align themselves with modernity. It is, therefore, necessary that future engagements between the two generations address such a gap.

\section{Extent of IGL envisaged for implementation}

One area emerging as a goal for intergenerational learning is the desire to address sustainability (Mannion, 2016). The older generation should be able to have a lifelong linkage with the younger generation. Mannion \& Adey (2011) note that any learning curricula be designed within the idea of improving relations among the generations within any context. There should be co-learning such that the younger generation draws from the older generation and vice versa for the curriculum to be the one envisaged. (George, et al., 2011: 402) Advocates that Intergenerational learning is a concept that can bring focus to the interconnectedness among generative spirits of all ages in society, break down the ideologies and physical barriers of age-segregated learning that define many of our educational environments, and lead to a powerful confluence of ideas, emotions, and actions in local communities and it shouldn' t for a short period (George, et al., 2011). Stakeholders, once they have benefited from the practical experience of being involved in these very relevant learning experiences. Young people, in particular, are keen to consider ways in which these can be expanded and developed to ensure they become part of life in the classroom and not just a 'one off' opportunity, for a small group of people, for a short period of time.

There should as well be some frequent evaluation to track the progress of the learning according to the initial planning. This will be to make sure that challenges are detected well in advance to avoid unwanted consequences. GWT said evaluation of the intergenerational project or activity should not be a separate item but part of ongoing evaluative work, incorporated into whatever system is currently being used. It is always important that the journey from start to finish is recorded to monitor the process for participants.

Academic leaders who understand these issues and are encouraged through policy, as well as inspection and monitoring regimes will be more likely to experiment with a more constructive approach to curriculum making, with parents, community members within local places. Further policy shifts and support are, therefore, needed before teachers will readily harness outside agencies of other sectors found in community groups. As contexts for learning beyond classrooms are becoming expected as the norm, intergenerational practice seems set to feed more directly into the core business of non-school-based learning (Mannion, 2016). Intergenerational practice and learning should be a growth area within all kinds and places of education since many of these could be vital to the creation of more inclusive, cohesive, and sustainable ways of life. Bratianu (2012) adds that to be effective, the intergenerational programs, as means of knowledge retention programs, should be planned in advance so that the holders' 
knowledge is captured at least two to three years before they retire. An idealistic way, is for the intergenerational learning programs being planned from the first day of the knowledgeholders' arrival through to the last, or well before retirement age. This is due to the fact, as articulated by Aemmi and Moonaghi (2017) that the intergenerational programs provide an opportunity of social engagement activities for older adults; this can help them to maintain mental and physical functioning levels and meaningful and impactful roles, post-retirement.

\section{What are the processes between DLM and CE in developing a collaborative intergenerational learning curriculum?}

The process that can assist in developing a collaborative intergenerational platform is when students take a practical ownership of DLM projects. That is when they get the gist of what DLM does and can align DLM objectives with the university' s proposed curriculum. It should be clear what the students envisage to also impact the lives of the elders since intergenerational learning is a reciprocal endeavour.

\section{Which institutions/role players would be involved in intergenerational learning?}

The role players involved in intergenerational learning are youths and the elders from any institution, institutions of higher learning, government departments, among others. When these stakeholders are fully involved, it makes the engagements easier as they each possess unique expertise to come to the table with.

\section{What is the nature of the curriculum, systems, and processes for intergenerational learning in universities?}

The nature of curriculum at the universities is such that the indigenous knowledge holders are not that well acknowledged for their knowledge like other experts. It has at times been suggested in some of the university engagements that indigenous knowledge holders should be invited to share expertise with students during lectures so that the students should hear first-hand information. Universities, hence, should consider affording knowledge holders a platform as per their suggestion. Mbembe (2016: 32) argues that 'there is something wrong when syllabuses designed to meet the needs of colonialism and apartheid should continue well into the liberation era' . This is why it is of paramount importance to bring about fundamental epistemological change at institution of higher learning (Mbembe (2016: 32).

Which appropriate traditional curriculum should we sample, implement, test, and evaluate towards the inclusive infusion of intergenerational learning in a university? Manners and discipline curriculum should be paid attention. There is a conduct young people have to portray, to show respect towards the elders. Unfortunately, such seems not to be happening and according to the elderly, this behaviour is seen as "modernity" . There are concerns that that the younger generations of today are no longer like the ones that used to take good care of the elderly. This was one of the reasons which prompted the universities or 
institutions of higher learning to bring together the two generations in order to explore and see what the recommendations could be for restoring respect amongst the communities.

\section{Author Biographies}

Professor Vhonani Olive Netshandama is a Decolonial Community-Based Participatory researcher with an interest in Indigenous Knowledge System (IKS), Social Innovation and sustainable livehood programmes. A 2016 distinguished women in science awardee by the department of science, and innovation and active Post Graduate Supervisor and a mentor of hundreds of undergraduate' s students across disciplines. She provides time and space for student' $s$ to discover themselves, learn about culture and heritage and engage in social enterprise and innovation ventures. She facilitates experiences for students and youth to develop an entrepreneurial mindset and design thinking. She has an interest in higher education' $s$ contribution to the societal impact and development of the intergenerational active citizenry. She is currently a Director of Community engagement Directorate at the University of Venda.

Nyadzani Dolphus Nevhudoli is a PhD Candidate at the University of Venda, department of African Studies, Faculty of Human, Social Sciences and Education. His PhD research focus is on a Participatory Evaluation of Bachelor of Indigenous Knowledge Systems at the University at the University of Venda. He holds two Master' s Degree in African Studies from University of Venda and University of Porto (Portugal). He has develop a great interest in Indigenous Knowledge Systems and Education Systems particularly in the Institutions of Higher Learning.

\section{References}

Aemmi, S.Z. \& Moonaghi, H.K. 2017. Intergenerational learning program: A bridge between generations. International Journal of Paediatrics, 5(12): 6713-6739.

Andreoletti, C. \& Howard, J.L., 2018. Bridging the generation gap: Intergenerational service learning benefits young and old. Gerontology \& Geriatrics Education, 39(1): 46-60.

Bernstein, L.E. 2006. Generations Working Together: What Everyone Needs to Know and Do.? The Walk The Talk Company.

Beynon, C. \& Lang, J. 2018. The more we get together, the more we learn: Focus on intergenerational and collaborative learning through singing. Journal of Intergenerational Relationships, 16(1-2): 45-63.

Bohlinger, S. \& Van Loo, J. 2010. Lifelong learning of aging workers to sustain employability and develop personality. In Working and Aging: Emerging Theories and Empirical Perspectives, Luxembourg: European Centre for the Development of Vocational Training, 28-57.

Boström, A.K. 2007. Lifelong Learning, Intergenerational Learning, and Social Capital: From Theory to Practice. Institute of International Education, Stockholm University.

Bratianu, C. 2012. A critical analysis of Nonaka' s model of knowledge dynamics. The Electronic Journal of Knowledge Management, 8(2): 193-200. 
Bratianu, C. \& Orzea, I. 2010. Tacit knowledge sharing in organizational knowledge dynamics. In Proceedings of the 2nd European Conference on Intellectual Capital. Lisbon, Portugal, March 29-30, pp. 107-1114.

Cohen-Mansfield, J. \& Jensen, B. 2017. Intergenerational programs in schools: Prevalence and perceptions of impact. Journal of Applied Gerontology, 36(3): 254-276.

Corrigan, T, McNamara, G. \& O'Hara, J. 2013. Intergenerational learning: A valuable learning experience for higher education students, Egitim Arastirmalari. Eurasian Journal of Educational Research, 52: 117-136.

Cortina, R. \& Earl, A.K. 2020. Advancing Professional Development for Teachers in Intercultural Education. Education Sciences, 10(12):1-12.

Cummings, S. M., Williams, M. M. \& Ellis, R.A. 2004. Impact of an intergenerational program on 4th graders' attitudes toward elders and school behaviors. Journal of Human Behavior in the Social Environment, 8(1): 43-61.

Duvall, J. \& Zint, M. 2007. A review of research on the effectiveness of environmental education in promoting intergenerational learning. Journal of Environmental Education, 38(4): 14-24.

Findsen, B. \& Formosa, M. 2012. Lifelong Learning in Later Life (Vol. 7). London: Springer Science \& Business Media.

Gallagher, C. \& Fitzpatrick, A. 2018. "It' s a Win-Win Situation" -Intergenerational Learning in Preschool and Elder Care Settings: An Irish Perspective: Practice. Journal of Intergenerational Relationships, 16(1-2), 26-44.

George, D., Whitehouse, C. \& Whitehouse, P. 2011. A model of intergenerativity: How the intergenerational school is bringing the generations together to foster collective wisdom and community health. Journal of Intergenerational Relationships, 9(4): 389-404.

Ghaye, T., Melander-Wikman, A., Kisare, M., Chambers, P., Bergmark, U., Kostenius, C. \& Lillyman, S. 2008. Participatory and appreciative action and reflection (PAAR)-democratizing reflective practices. Reflective practice, 9(4): 361-397.

Hake, B.J. 2014. What grows in gardens? Perspectives on Intergenerational Learning in urban spaces. In Schmidt-Hertha, B. \& Krašovec, S.J. (eds.) Learning across Generations in Europe: Contemporary Issues in Older Adult Education. Rotterdam: Sense Publishers, 155-166.

Hatten-Yeo, A., 2007. Intergenerational Practice: Active Participation Across the Generations. Stoke on Trent: Beth Johnson Foundation.

Hoff, A. 2007. Intergenerational learning as an adaptation strategy in aging knowledge societies. In: European Commission (ed.) Education, Employment, Europe. Warsaw. National Contact Point for Research Programmes of the European Union, 126-129

Jarvis, P. 2009. The human quest: Philosophical perspectives on lifelong learning. E-Journal of A/l India Association for Educational Research, 21(2): 4-11.

Johnson, B. 2008. Learning Through Practices: Generations working Together. Scottish Mentoring Network. Scotland. 
Kaplan, M. \& Sánchez, M. 2014. Intergenerational programs and policies in aging societies. In Harper, S., Hamblin, K., Hoffman, J., Howse, K. \& Leeson, G. (eds.) International Handbook on Ageing and Public Policy. Cheltenham: Edward Elgar Publishing. 367-383.

Kearney, J., Wood, L. \& Zuber-Skerritt, O. 2013. Community-university partnerships: Using participatory action learning and action research (PALAR). Gateways: International Journal of Community Research and Engagement, 6: 113-130.

Kolb, A.Y. \& Kolb, D.A. 2005. Learning styles and learning spaces: Enhancing experiential learning in higher education. Academy of Management Learning \& Education, 4(2): 193-212.

Lyu, K., Xu, Y., Cheng, H. \& Li, J., 2020. The implementation and effectiveness of intergenerational learning during the COVID-19 pandemic: Evidence from China. International Review of Education, 66(5): 833-855.

Mannion, G. \& Adey, C. 2011. Place-based education is an intergenerational practice. Children Youth and Environments, 21(1), 35-58.

Mannion, G. 2016. Intergenerational education and learning: We are in a new place. In Punch, S., Vanderbeck, R. \& Skelton, T. (eds.) Families, Intergenerationality, and Peer Group Relations. Singapore: Singer, 1-21.

Maloney, T., Hayes, N., Crawford-Garrett, K. \& Sassi, K. 2019. Preparing and supporting teachers for equity and racial justice: Creating culturally relevant, collective, intergenerational, cocreated spaces. Review of Education, Pedagogy, and Cultural Studies, 41(4-5), 252-281.

Mbiti, J. 1990. African Religious and Philosophies. New York: New Hampshire: Heinemann Educational Books Inc.,

Mbembe, A. 2016, Decolonising the university: New directions. Arts \& Humanities in Higher Education 15(1): 29-45.

Moichela, K.Z., 2017. Integration of indigenous knowledge systems in the curriculum for basic education: possible experiences of Canada. Unpublished PhD diss., The University of South Africa, South Africa.

Newman, S. \& Hatton-Yeo, A. 2008. Intergenerational learning and the contributions of older people. Ageing Horizons, 8: 31-39.

Orzea, I. \& Bratianu, C. 2012. Intergenerational learning in ageing societies. In Proceedings of the 9th International Conference on Intellectual Capital, Knowledge Management and Organizational Learning-/CICKM2012, Universidad del Rosario and Universidad Jorge Tadeo Lozano.

Perrin, J. 2014. Features of engaging and empowering experiential learning programs for college students. Journal of University Teaching and Learning Practice, 11(2).

Phillipson, C. \& Ogg, J. 2010. Active Ageing and Universities: Engaging Older Learners. Universities UK, London.

Pinto, T.A. 2011. Why is Intergenerational learning not an Academic Discipline Yet? Journal of Intergenerational Relationships, 9(1): 117-119. 
Pstross, M., Corrigan, T., Knopf, R. C., Sung, H., Talmage, C. A., Conroy, C. \& Fowley, C. 2017. The benefits of intergenerational learning in higher education: Lessons learned from two age friendly university programs. Innovative Higher Education, 42(2): 157-171.

Ramoupi, N.L.L., 2014. African research and scholarship: 20 years of lost opportunities to transform higher education in South Africa' , Ufahamu: A Journal of African Studies, 38(1): 269-286.

Ropes, D. 2013. Intergenerational learning in organizations. European Journal of Training and Development, 37(8): 713-727.

Sanchez, M., Whitehouse, P. \& Johnston, L. 2018. Intergenerational Learning and Education in Schools and Beyond. Journal of Intergenerational Relationships, 16(1-2): 1-4.

Sharma, R., 2017. Intergenerational Learning. Journal of Gerontology and Geriatric Research, 6(3).

Stephan, A. 2021. Intergenerational Learning in the Family as an Informal Learning Process: A Review of the Literature. Journal of Intergenerational Relationships, 19(4): 441-458.

Togonu-Bickersteth, F. 2014. Intergenerational interactions: rethinking our assumptions, methodology, and program design. Editorial Comment.. Journal of Intergenerational Relationships, 12(3): 221-225.

Tutu, D., Tutu, M.A., Kae-Kazim, H. \& Badaki, Y. 2014. The Book of Forgiving: The Fourfold Path for Healing Ourselves and Our World. San Francisco: Haperone.

Twenge, J.M. 2013. The evidence for generation me and against generation we. Emerging Adulthood, 1(1): 11-16.

Van Wyk, B. \& Higgs, P. 2012. The future of university research in Africa. In Barnett, R. (ed.) The Future University. London: Routledge, 190-198.

Wrenn, J. \& Wrenn, B. 2009. Enhancing learning by integrating theory and practice. International Journal of Teaching and Learning in Higher Education, 21(2): 258-265.

Wood, L. \& Zuber-Skerrit, O. 2013. PALAR as a methodology for community engagement by faculties of education. South African Journal of Education, 33(4): 1-15. 